\title{
ANALISIS KARAKTERISTIK POLA BELANJA KELUARGA DENGAN ANALISIS KLASTER
}

\author{
Nur Arina Hidayati \\ Program Studi Pendidikan Matematika FKIP UAD \\ J1. Prof. Dr. Soepomo, SH. Janturan Yogyakarta \\ nurarinahidayati@gmail.com
}

\begin{abstract}
ABSTRAK
Analisis klaster merupakan salah satu alat untuk mengelompokkan sejumlah $\mathrm{n}$ obyek berdasarkan $\mathrm{p}$ variat yang secara relatif mempunyai kesamaan karakteristik di antara obyek-obyek tersebut. Tujuan utama analisis klaster adalah menempatkan sekumpulan objek ke dalam dua grup atau lebih berdasarkan kesamaan objek atas dasar berbagai karakteristik.

Segmentasi pola belanja merupakan bagian dari segmentasi pasar dalam kategori psikografi. Segmentasi ini mengelompokkan pasar dalam variabel gaya hidup. Dalam hal ini gaya hidup berdasarkan pola belanja.

Kesimpulan dari segmentasi pola belanja dengan studi kasus data rata-rata pengeluaran belanja makanan dari beberapa keluarga di negara Perancis, diperoleh Klaster 1 yang beranggotakan responden dengan tipe keluarga MA dan EM dengan jumlah anak 2 dan 3 memiliki prosentase ratarata belanja $79 \%$ dari seluruh transaksi. Klaster 2 yang beranggotakan responden dengan tipe keluarga MA dan EM dengan jumlah anak 4 dan 5, dan tipe CA dengan jumlah anak 2, memiliki prosentase rata-rata belanja 106\%. Klaster 3 yang beranggotakan responden dengan tipe keluarga CA dengan jumlah anak 3, 4 dan 5. Karakter khusus dari keluarga ini adalah mempunyai minat belanja yang tinggi dibanding klaster yang lain, tampak dari prosentase rata-rata belanja $118 \%$ dari seluruh transaksi
\end{abstract}

Kata kunci : Analisis klaster, segmentasi pasar, karakteristik

\begin{abstract}
Cluster analysis is a tool for classifying $n$ objects based on $p$ variat relatively have a common characteristic among these objects. The main goal is to put a set of cluster analysis of objects into two or more groups based on similarity of objects on the basis of various characteristics.

Segmentation pattern of spending is part of the category of psychographic segmentation. This segmentation variable grouping in the lifestyle market. In this case a lifestyle based on spending patterns.

Conclusion of the segmentation pattern of shopping with a case study data is the average food expenditure of a few families in the country of France, obtained Cluster 1 is composed of respondents with family type MA and EM with child number 2 and 3 have an average percentage of spending 79\% of all transaction. Cluster 2 is composed of respondents with family type MA and $E M$ with child number 4 and 5, and the type of CA with child number 2, had an average percentage of spending 106\%. Cluster 3 is composed of respondents with family-type CA with child number 3 , 4 and 5. The special character of this family have an interest expenditure is higher than the other clusters, it appears from the average percentage of spending $118 \%$ of all transactions
\end{abstract}

Keywords : Cluster analysis, Segmentation pattern, Characteristic 


\section{Pendahuluan}

Analisis klaster merupakan salah satu tehnik multivariate metode interdependensi (saling ketergantungan). Oleh karena itu, dalam analisis klaster tidak ada perbedaan antara variabel bebas (independent variabel) dan variabel terikat (dependent variabel).

Analisis klaster digunakan untuk mengelompokkan data observasi yang hanya berdasarkan pada informasi yang ditemukan dalam data, dimana data tersebut harus menggambarkan observasi dan hubungannya.

Analisis klaster adalah tehnik yang digunakan untuk menggabungkan observasi ke dalam kelompok klaster atau klaster (Sharma, 1996:185), sedemikian sehingga:

1. Setiap kelompok atau klaster homogen mempunyai karakteristiktertentu. Hali ini berarti bahwa observasi dalam setiap kelompok sama dengan observasi lain dalam satu kelompok yang sama;

2. Setiap kelompok seharusnya berbeda dari kelompok lain dengan karakteristik yang sama. Hal ini berarti bahwa observasi dalam kelompok yang satu seharusnya berbeda dari observasi dalam kelompok lain.
Tujuan utama analisis klaster adalah menempatkan sekumpulan objek ke dalam dua grup atau lebih berdasarkan kesamaan objek atas dasar berbagai karakteristik. Hasil klaster suatu obyek harus memiliki internal (within cluster) homoginitas yang tinggi dan memiliki eksternal (between cluster) heteroginitas yang tinggi. Semakin besar kemiripan (homoginitas) dalam kelompok dan perbedaan antar kelompok maka klastering akan lebih baik atau lebih berbeda (Tan et al,2006:490).

Dalam analisis klaster, pengelompokan ke dalam klaster dilakukan dengan menggunakan tehniktehnik yang berawal dari kemiripan antar semua pasangan observasi. Kemiripan ini didasarkan pada berapa ukuran jarak anatra observasi satu dengan observasi yang lain.

Pada prinsipnya analisis klaster merupakan proses untuk mereduksi sejumlah objek yang besar menjadi lebih sedikit yang disebut klaster. Analisis klaster disebut juga Q-analysis, classification analysis, pengenalan pola (pattern recognition), analisis segmentasi (numerical taxonomy).

\section{Segmentasi pasar}

Segmentasi pasar adalah proses pemisahan sebuah pasar menjadi 
kelompok-kelompok pembeli atau produk yang sejenis dan memiliki kelompok (atau kelompok-kelompok) yang paling tepat untuk dilayani perusahaan (Peter, 2000). Hal ini merupakan upaya paling efektif dalam menyingkapi peluang pasar. Beberapa jenis segmentasi utama adalah geografi, demografi, psikografi, perilaku dan manfaat (Morissan, 2009). Secara garis besar penjelasan masing-masing jenis sebagai berikut:

1. Segmentasi Geografi, merupakan pembagian pasar menjadi unit-unit geografis yang berbeda. Misalnya: wilayah, negara negara bagian, propoinsi, kota dan kepulauan.

2. Segmentasi Demografi, dimana pasar dikelompokkan berdasarkan variabel-variabel pendapatan, jenis kelamin, pendidikan, jumlah penduduk, usia, ukuran keluarga, pekerjaan, agama, ras, generasi, kewarganegaraan dan kelas sosial.

3. Segmentasi Psikografi, mengelompokkan pasar dalam variabel gaya hidup, nilai dan kepribadian. Gaya hidup juga ditunjukkan oleh orang-orang yang menonjol pada kelas sosial. Minat terhadap suatu produk juga dipengaruhi oleh gaya hidup.

4. Segmentasi Perilaku, membagi kelompok berdasarkan status pemakai, kejadian, tingkat penggunaan, status kesetiaan, tahap kesiapan pembeli, dan sikap. Pasar disini dapat dikelompokkan menjadi bukan pemakai, bekas pemakai, pemakai potesial, pemakai pertama kali, dan pemakai tetap dari suatu produk.

5. Segmentasi Manfaat

Mengklasifikasi pasar berdasarkan atribut/nilai atau manfaat yang terkandung dalam suatu produk.

Pada tulisan ini digunakan segmentasi psikografi, dimana objek dikelompokkan bersadarkan produkproduk bahan olahan makanan yang dibeli dalam sebuah supermarket. Berdasarkan pola belanja terhadap produk-produk tersebut, akan diketahui pola hidup objek-objek tersebut.

\section{Metode Pengelompokan (Clustering) Secara umum metode pengelompokan dalam analisis klaster dibedakan menjadi metode hirarki (Hierarchical Clustering Methode) dan metode non hirarki (Nonhierarchical Clustering Methode).}

\section{A. Metode Hirarki}

Pada dasarnya metode ini dibedakan menjadi dua metode pengelompokan, yaitu: 
1. Metode Agglomeratif

Proses pengelompokan dengan pendekatan aglomeratif (Down to Top) dimulai dengan $n$ klaster sehingga masing-masing klaster memiliki tepat satu objek, kemudian menentukan dua klaster terdekat dan menggabungkan dua klaster tersebut menjadi satu klaster baru. Proses penggabungan dua klaster ini diulangi sampai diperoleh satu klaster yang memuat semua himpunan data. Hasil analisis klaster dari metode ini dapat disajikan dalam bentuk dendogram.

Dalam metode Agglomeratif ini terdapat lima metode yang cukup terkenal, yaitu:

a. Single Linkage

Prosedur ini didasarkan pada jarak terkecil. Jika dua obyek terpisah oleh jarak yang pendek maka kedua oyek tersebut akan akan digabung menjadi satu klaster, demikian seterusnya.

b. Complete Linkage

$\begin{array}{llr}\text { Berlawanan } & \text { dengan } & \text { Single } \\ \text { Linkage, } & \text { prosedur } & \text { ini }\end{array}$ pengelompokannya berdasarkan jarak terjauh.

c. Average Linkage

Prosedur ini hampir sama dengan Single Linkage dan
Complete Linkage, namun criteria yang digunakan adalah rata-rata jarak seluruh individu dalam suatu klaster dengan jarak seluruh individu dalam klaster yang lain.

d. Ward's Methode

Jarak antara dua klaster dalam metode ini berdasarkan total sum of square dua klaster pada masing-masing variabel.

e. Centroid method

Jarak dua klaster dalam metode ini berdasarkan jarak centroid dua klaster yang bersangkutan.

2. Metode Divisif

Proses pengelompokan dengan pendekatan metode divisive (Top to Down) dimulai dengan $n$ objek yang dikelompokkan menjadi satu klaster, kemudian klaster tersebut dipartisi ke dalam dua klaster pada setiap langkah sampai diperoleh $n$ klaster dengan setiap klaster memiliki satu objek.

\section{B. Metode Non-Hirarki}

Dalam metode ini data dibagi dalam $k$ partisi, setiap partisi mewakili sebuah klaster. Secara umum proses metode non-hirarki sebagai berikut:

1. Pilih $k$ centroid klaster awal atau seed, dimana $k$ merupakan jumlah klaster yang diinginkan 
2. Tempatkan setiap observasi ke dalam klaster yang terdekat

3. Tempatkan kembali setiap observasi ke dalam $\mathrm{k}$ klaster menurut aturan penghentian yang sudah di tentukan

4. Proses berhenti jika tidak ada observasi yang berpindah lagi, jika belum ulangi langkah kedua.

\section{Langkah-langkah melakukan analisis}

\section{klaster}

Dalam tulisan ini, digunakan metode pengklastersan hirarki metode agglomeratif. Adapun langkahlangkahnya adalah sebagai berikut:

1. Langkah ini dimulai dengan $n$ klaster sehingga masing-masing klaster memiliki tepat satu objek.

2. Menentukan dua klaster terdekat dan menggabungkan dua klaster tersebut menjadi satu klaster baru. Untuk menentukan jarak terdekat antara dua claster digunakan metode ward atau varians method. Metode ini bertujuan memperoleh klaster yang memiliki varians interval klaster yang sekecil mungkin, yaitu dengan mengkuadratkan jarak Euclid (Squared Euclidean Distanc)e antar klaster.

3. Ulangi langkah ke-2 sehingga berakhir sampai diperoleh satu klaster yang memuat semua himpunan data. Data Out put dalam SPSS berupa dendogram.

4. Lakukan profilisasi dan interpretasi klaster. Interpretasi dilakkan untuk mencari karakteristik tiap klaster yang khas.

\section{Olah Data}

Dalam tulisan ini, data yang digunakan adalah data rata-rata pengeluaran belanja makanan dari beberapa keluarga di negara Perancis dengan tipe keluarga yang berbeda (tipe MA, tipe EM, tipe CA ) dengan jumlah anak 2,3, 4 atau 5. Data ini diambil dari Lebart, Morineau dan Fenelon (1982) yang disajikan dalam tabel berikut ini :

Tabel 1. Daftar Belanja Keluarga di Perancis

\begin{tabular}{|r|l|r|r|r|r|r|r|r|}
\hline No & Type & \multicolumn{1}{l|}{ Bread } & \multicolumn{1}{l|}{ Vegetables } & \multicolumn{1}{l|}{ Fruits } & \multicolumn{1}{l|}{ Meat } & Poultry & Milk & Wine \\
\hline 1 & MA2 & 332 & 428 & 354 & 1437 & 526 & 247 & 427 \\
\hline 2 & EM2 & 293 & 559 & 388 & 1527 & 567 & 239 & 258 \\
\hline 3 & CA2 & 372 & 767 & 562 & 1948 & 927 & 235 & 433 \\
\hline 4 & MA3 & 406 & 563 & 341 & 1507 & 544 & 324 & 407 \\
\hline 5 & EM3 & 386 & 608 & 396 & 1501 & 558 & 319 & 363 \\
\hline 6 & CA3 & 438 & 843 & 689 & 2345 & 1148 & 243 & 341 \\
\hline 7 & MA4 & 534 & 660 & 367 & 1620 & 638 & 414 & 407 \\
\hline
\end{tabular}




\begin{tabular}{|r|l|r|r|r|r|r|r|r|}
\hline 8 & EM4 & 460 & 699 & 484 & 1856 & 762 & 400 & 416 \\
\hline 9 & CA4 & 385 & 789 & 621 & 2366 & 1149 & 304 & 282 \\
\hline 10 & MA5 & 655 & 776 & 423 & 1848 & 759 & 495 & 486 \\
\hline 11 & EM5 & 584 & 995 & 548 & 2056 & 893 & 518 & 319 \\
\hline 12 & CA5 & 515 & 1097 & 887 & 2630 & 1167 & 561 & 284 \\
\hline & $\begin{array}{l}\text { Rata - } \\
\text { rata }\end{array}$ & $\mathbf{4 4 6 . 7}$ & $\mathbf{7 3 2 . 0}$ & $\mathbf{5 0 5 . 0}$ & $\mathbf{1 8 8 6 . 8}$ & $\mathbf{8 0 3 . 2}$ & $\mathbf{3 5 8 . 3}$ & $\mathbf{3 6 8 . 6}$ \\
\hline
\end{tabular}

Posedur olah data dilakukan dengan SPSS 15.00, dengan Out Put sebagai berikut:

\section{Cluster}

[DataSet1] E: \S2 Matematika UGM $\backslash$ UJIAN Data Mining $\backslash F r e n c h$ Food Data.sav

Case Processing Summarya,b

\begin{tabular}{|c|c|c|c|c|c|}
\hline \multicolumn{6}{|c|}{ Cases } \\
\hline \multicolumn{2}{|c|}{ Valid } & \multicolumn{2}{|c|}{ Missing } & \multicolumn{2}{|c|}{ Total } \\
\hline$N$ & Percent & $N$ & Percent & $N$ & Percent \\
\hline 12 & 100.0 & 0 & .0 & 12 & 100.0 \\
\hline
\end{tabular}

a. Squared Euclidean Distance used

b. Ward Linkage

\section{Ward Linkage}

Agglomeration Schedule

\begin{tabular}{|l|r|r|r|r|r|r|}
\hline \multirow{2}{*}{ Stage } & \multicolumn{3}{|c|}{ Cluster Combined } & & \multicolumn{2}{|c|}{$\begin{array}{c}\text { Stage Cluster First } \\
\text { Appears }\end{array}$} \\
\cline { 2 - 3 } \cline { 5 - 6 } & Cluster 1 & Cluster 2 & Coefficients & Cluster 1 & Cluster 2 & Next Stage \\
\hline 1 & 4 & 5 & 3821.500 & 0 & 0 & 3 \\
3 & 6 & 9 & 12818.000 & 0 & 0 & 9 \\
4 & 2 & 4 & 36425.833 & 0 & 1 & 4 \\
5 & 1 & 2 & 65855.250 & 0 & 3 & 10 \\
6 & 8 & 10 & 96691.750 & 0 & 0 & 6 \\
7 & 7 & 8 & 153977.917 & 0 & 5 & 8 \\
8 & 3 & 11 & 255492.417 & 0 & 0 & 8 \\
9 & 3 & 7 & 430601.250 & 7 & 6 & 10 \\
10 & 6 & 12 & 632336.083 & 2 & 0 & 11 \\
11 & 1 & 3 & 1334487.56 & 4 & 8 & 11 \\
& 1 & 6 & 3435249.75 & 10 & 9 & 0 \\
\hline
\end{tabular}


Berdasarkan Tabel Agglomeration

Schedule diatas diperoleh keterangan sebagai berikut :

Pada tahap pertama obyek yang dipasangkan adalah responden $\mathbf{4}$ dan 5 karena pasangan ini memiliki koefisien jarak paling rendah, dimana pada saat itu objek-objek yang lain sama sekali belum memperoleh pasangan.Oleh karena itu, pada tahap ini jumlah klaster ada 11. Pada baris pertama ini, pada kolom next page tertulis 3. Artinya pada tahap ke-2, pasangan 4 dan 5 akan mendapat anggota baru, yaitu responden yang ke-4.
Tahap ke dua, responden 6 dan 9 dipasangkan. Artinya, koefisien jarak terendah yang kedua adalah pasangan iresponden ini. Kemudian pada kolom next page tertulis 9, artinya pada tahap ke-8, pasangan 6 dan 9 akan mendapat anggota baru. Pada tahap ini jumlah klaster ada $\mathbf{1 0 .}$

Demikian seterusnya, pada setiap tahap jumlah klaster berkurang satu, sehingga pada tahap tahap yang terakhir yaitu ke-11, semua responden menjadi satu klaster

Vertical Icicle

\begin{tabular}{|c|c|c|c|c|c|c|c|c|c|c|c|c|c|c|c|c|c|c|c|c|c|c|c|}
\hline \multirow[b]{2}{*}{ Number of clusters } & \multicolumn{23}{|c|}{ Case } \\
\hline & 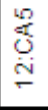 & & \begin{tabular}{l}
$\mathbb{J}$ \\
\multirow{\sigma}{*}{}
\end{tabular} & & $\underset{0}{\mathscr{S}}$ & & $\frac{6}{5}$ & & $\underset{\dot{\varpi}}{\stackrel{\Xi}{\Xi}}$ & & $\sum_{i=0}^{ \pm}$ & & 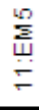 & & 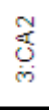 & & $\underset{i}{\stackrel{M}{\leftrightarrows}}$ & & 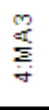 & & 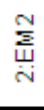 & & 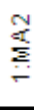 \\
\hline 1 & $\mathrm{X}$ & $\mathrm{X}$ & $\mathrm{X}$ & $\mathrm{X}$ & $X$ & $\bar{X}$ & $\mathrm{X}$ & $\mathrm{X}$ & $\mathrm{X}$ & $\mathrm{X}$ & $\mathrm{X}$ & $\bar{X}$ & $\mathrm{X}$ & $\mathrm{X}$ & $\mathrm{X}$ & $\mathrm{X}$ & $\mathrm{X}$ & $\mathrm{X}$ & $\mathrm{X}$ & $\mathrm{X}$ & $\mathrm{X}$ & $\mathrm{X}$ & $\mathrm{X}$ \\
\hline 2 & $x$ & $x$ & $x$ & $x$ & $\mathrm{x}$ & & $x$ & $x$ & $x$ & $x$ & $x$ & $x$ & $x$ & $x$ & $x$ & $x$ & $\mathrm{x}$ & $x$ & $x$ & $x$ & $x$ & $x$ & $x$ \\
\hline 3 & $x$ & $x$ & $\mathrm{x}$ & $\mathrm{x}$ & $\mathrm{x}$ & & $\mathrm{x}$ & $\mathrm{x}$ & $x$ & $\mathrm{x}$ & $\mathrm{X}$ & $x$ & $\mathrm{x}$ & $x$ & $\mathrm{x}$ & & $\mathrm{x}$ & $\mathrm{x}$ & $\mathrm{x}$ & $\mathrm{x}$ & $\mathrm{x}$ & $\mathrm{x}$ & $x$ \\
\hline 4 & $x$ & & $\mathrm{x}$ & $\mathrm{X}$ & $\mathrm{x}$ & & $x$ & $x$ & $x$ & $\mathrm{x}$ & $x$ & $x$ & $\mathrm{x}$ & $x$ & $x$ & & $x$ & $x$ & $\mathrm{x}$ & $x$ & $x$ & $\mathrm{x}$ & $x$ \\
\hline 5 & $x$ & & $\mathrm{X}$ & $\mathrm{X}$ & $\mathrm{x}$ & & $X$ & $X$ & $X$ & $X$ & $X$ & & $X$ & $X$ & $X$ & & $X$ & $X$ & $X$ & $X$ & $X$ & $X$ & $X$ \\
\hline 6 & $x$ & & $X$ & $x$ & $X$ & & $x$ & $X$ & $X$ & $x$ & $X$ & & $X$ & & $X$ & & $x$ & $x$ & $x$ & $x$ & $x$ & $x$ & $x$ \\
\hline 7 & $x$ & & $x$ & $X$ & $\mathrm{X}$ & & $x$ & $x$ & $x$ & & $x$ & & $x$ & & $x$ & & $x$ & $x$ & $x$ & $x$ & $x$ & $x$ & $x$ \\
\hline 8 & $x$ & & $X$ & $X$ & $X$ & & $X$ & & $X$ & & $X$ & & $X$ & & $X$ & & $X$ & $X$ & $X$ & $\mathrm{X}$ & $X$ & $X$ & $X$ \\
\hline 9 & $x$ & & $X$ & $X$ & $X$ & & $X$ & & $X$ & & $X$ & & $x$ & & $X$ & & $X$ & $X$ & $X$ & $X$ & $X$ & & $X$ \\
\hline 10 & $x$ & & $X$ & $X$ & $X$ & & $X$ & & $X$ & & $X$ & & $X$ & & $X$ & & $X$ & $X$ & $X$ & & $X$ & & $X$ \\
\hline 11 & $x$ & & $X$ & & $X$ & & $X$ & & $X$ & & $X$ & & $x$ & & $X$ & & $X$ & $X$ & $X$ & & $X$ & & $X$ \\
\hline
\end{tabular}




\section{Dendrogram}

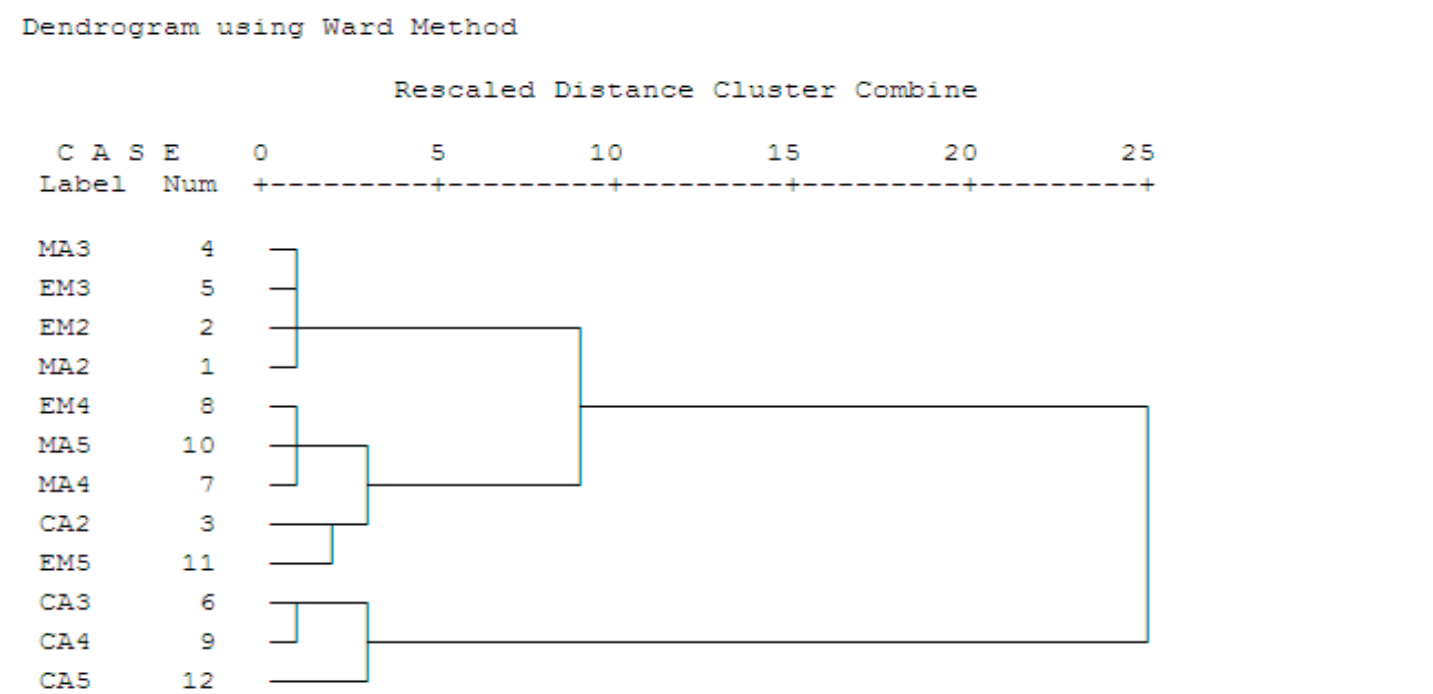

Berkaitan dengan berapa banyaknya klaster atau jumlah klaster yang dapat terbentuk dari kasus tersebut, dendogram diatas dapat dijadikan acuan untuk menentukan jumlah cluster. Dari dendogram di atas dapat terlihat jumlah klaster yang dapat dibentuk adalah tiga klaster, dengan anggota sebagai berikut :

Tabel 2. Pengelompokan Keluarga Berdasarkan Klaster

\begin{tabular}{|c|c|c|c|c|c|}
\hline Klaster & Case & Klaster & Case & Klaster & Case \\
\hline \multirow{5}{*}{ Klaster 1} & $4:$ MA3 & \multirow{5}{*}{ Klaster 2} & $6:$ EM4 & \multirow{5}{*}{ Klaster 3} & $6: \mathrm{CA} 3$ \\
\hline & $5:$ EM3 & & $10:$ MA5 & & $9:$ CA4 \\
\hline & $2:$ EM2 & & $7:$ MA4 & & $12:$ CA5 \\
\hline & $1:$ MA2 & & $3: \mathrm{CA} 2$ & & \\
\hline & & & $11:$ EM5 & & \\
\hline
\end{tabular}

Tahap Selanjutnya Adalah

Interpretasi dan Pembuatan Profil.

Untuk menginterpretasikan

klaster dam membuat profil, digunakan rata-rata setiap klaster pada setiap variable (centroid). Berikut tabel Profil dari masingmasing Klaster : 
Tabel 3. Profil Klaster Satu

\begin{tabular}{|r|l|c|c|c|c|c|c|c|}
\hline No & type & Bread & Vegetables & Fruits & Meat & Poultry & Milk & Wine \\
\hline 4 & MA3 & 406 & 563 & 341 & 1507 & 544 & 324 & 407 \\
\hline 5 & EM3 & 386 & 608 & 396 & 1501 & 558 & 319 & 363 \\
\hline 2 & EM2 & 293 & 559 & 388 & 1527 & 567 & 239 & 258 \\
\hline 1 & MA2 & 332 & 428 & 354 & 1437 & 526 & 247 & 427 \\
\hline Rata - rata & 354.25 & 539.5 & $\begin{array}{c}369.7 \\
5\end{array}$ & 1493 & 548.75 & $\begin{array}{c}282.2 \\
5\end{array}$ & $\begin{array}{c}363.7 \\
5\end{array}$ \\
\hline $\begin{array}{c}\text { Prosentase } \\
\text { Belanja }\end{array}$ & $79 \%$ & $73 \%$ & $73 \%$ & $79 \%$ & $68 \%$ & $79 \%$ & $99 \%$ \\
\hline
\end{tabular}

Tabel 4. Profil Klaster Dua

\begin{tabular}{|r|l|c|c|c|c|c|c|c|}
\hline No & type & Bread & Vegetables & Fruits & Meat & Poultry & Milk & Wine \\
\hline 8 & EM4 & 460 & 699 & 484 & 1856 & 762 & 400 & 416 \\
\hline 10 & MA5 & 655 & 776 & 423 & 1848 & 759 & 495 & 486 \\
\hline 7 & MA4 & 534 & 660 & 367 & 1620 & 638 & 414 & 407 \\
\hline 3 & CA2 & 372 & 767 & 562 & 1948 & 927 & 235 & 433 \\
\hline 11 & EM5 & 584 & 995 & 548 & 2056 & 893 & 518 & 319 \\
\hline \multicolumn{2}{|c|}{ Rata - rata } & 521 & 779.4 & 476.8 & 1865.6 & 795.8 & 412.4 & 412.2 \\
\hline $\begin{array}{c}\text { Prosentase } \\
\text { Belanja }\end{array}$ & $117 \%$ & $106 \%$ & $94 \%$ & $99 \%$ & $99 \%$ & $115 \%$ & $112 \%$ \\
\hline
\end{tabular}

Tabel 5. Profil Klaster Tiga

\begin{tabular}{|r|l|c|c|c|c|c|c|c|}
\hline No & type & Bread & Vegetables & Fruits & Meat & Poultry & Milk & Wine \\
\hline 6 & CA3 & 438 & 843 & 689 & 2345 & 1148 & 243 & 341 \\
\hline 9 & CA4 & 385 & 789 & 621 & 2366 & 1149 & 304 & 282 \\
\hline 12 & CA5 & 515 & 1097 & 887 & 2630 & 1167 & 561 & 284 \\
\hline Rata - rata & 446.00 & 909.67 & 732.33 & 2447.00 & 1154.67 & 369.33 & 302.33 \\
\hline $\begin{array}{c}\text { Prosentase } \\
\text { Belanja }\end{array}$ & $100 \%$ & $123 \%$ & $145 \%$ & $130 \%$ & $144 \%$ & $103 \%$ & $82 \%$ \\
\hline
\end{tabular}

klaster, disajikan rekapitulasi prosentase belanja dari masingmasing klaster sebagai berikut Untuk memudahkan dalam mengamati karakteristik pola belanja masingmasing: 
Tabel 6. Prosentase Pola Belanja

\begin{tabular}{|l|c|c|c|}
\hline & $\begin{array}{c}\text { Prosentase Pola } \\
\text { Belanja Klaster 1 }\end{array}$ & $\begin{array}{c}\text { Prosentase Pola } \\
\text { Belanja Klaster 2 }\end{array}$ & $\begin{array}{c}\text { Prosentase Pola } \\
\text { Belanja Klaster 3 }\end{array}$ \\
\hline Bread & $79 \%$ & $117 \%$ & $100 \%$ \\
\hline Vegetables & $73 \%$ & $106 \%$ & $123 \%$ \\
\hline Fruits & $73 \%$ & $94 \%$ & $145 \%$ \\
\hline Meat & $79 \%$ & $99 \%$ & $130 \%$ \\
\hline Poultry & $68 \%$ & $99 \%$ & $144 \%$ \\
\hline Milk & $79 \%$ & $115 \%$ & $103 \%$ \\
\hline Wine & $99 \%$ & $112 \%$ & $82 \%$ \\
\hline Rata-rata & $79 \%$ & $106 \%$ & $118 \%$ \\
\hline
\end{tabular}

\section{Kesimpulan}

Analisa tabel Prosentase Pola Belanja:

1. Klaster $\mathbf{1}$ yang beranggotakan responden dengan tipe keluarga MA dan EM dengan jumlah anak 2 dan 3 memiliki prosentase ratarata belanja $\mathbf{7 9 \%}$ dari seluruh transaksi. Dapat dilihat prosentase belanja keluarga ini paling kecil dibandingkan tipe keluarga yang lain. Tipe keluarga ini jarang mengkonsumsi olahan daging itik, terlihat dari prosentase yang kecil jika dibandingkan dengan item yang lain, yaitu sebesar 68\%. Satu hal yang menarik dari tipe keluarga ini adalah keluarga ini mempunyai karakter suka mengkonsumsi wine, tampak dari prosentase yang paling tinggi dibandingkan dengan item yang lain yaitu $\mathbf{9 9 \%}$, selain itu juga jika dibandingkan dengan klaster yang lain konsumsi wine tipe keluarga ini juga cukup tinggi bahkan melebihi klaster yag ke 3 walaupun klaster yang ketiga prosentase belanjanya lebih besar.

2. Klaster 2 yang beranggotakan responden dengan tipe keluarga MA dan EM dengan jumlah anak 4 dan 5, dan tipe CA dengan jumlah anak 2, memiliki prosentase ratarata belanja $106 \%$ dari seluruh transaksi. Keluarga ini nampaknya mempunyai kebiasaan sarapan dengan bread dan milk, dilihat dari prosentase pembelian yang cukup tinggi jika dibandingkan dengan item yang lain dan klaster yang lain, yaitu prosentase bread sebesar $117 \%$ dan prosentase milk $115 \%$.

3. Klaster 3 yang beranggotakan responden dengan tipe keluarga CA dengan jumlah anak 3, 4 dan 5. Karakter khusus dari keluarga ini adalah mempunyai sense belanja yang tinggi dibanding klaster yang 
lain, tampak dari prosentase ratarata belanja $118 \%$ dari seluruh transaksi. Akan tetapi tipe keluarga ini cukup memperhatikan kesehatan, dapat dilihat dari prosentase belanja buah yang sangat tinggi baik dibandingkan dengan item yang lain maupun klaster tipe keluarga yang lain (145\%), selain itu pula konsumsi wine dari tipe kelurga ini paling kecil jika dibandingkan dengan yang lain $\mathbf{( 8 2 \% )}$. Keluarga ini juga sangat menyukai olahan daging itik (144\%).

\section{Pustaka}

Ghozali, I., Aplikasi Multivariat dengan Program SPSS, Badan Penerbit U ndip, Semarang, 2001

Morissan, Sales-Marketing Pokok Bahasan: Segmentasi Pasar, 2009, URL:

http://pksm.mercubuana.ac.id?ne w/elearning/files modul/41003-6256559724556.pdf

Peter, J. P and Olson, J.C., Consumer Behavior : Perilaku Konsumen dan Strategi Pemasaran, Erlangga, Jakarta, 2000.

Rosiatun, A., Widiharih,T., Safitri, D., Analisis Klaster Untuk Segmentasi Pemirsa Program Berita Sore Stasiun TV Swasta, FMIPA Universitas Diponegoro.

Sharma, S., Applied Multivariate Techniques, John Willey \&Sons, New York, 1996.

Simamora, B., Analisis Multivariat Pemasaran, Gramedia Pustaka Utama, Jakarta, 2005.
Tan, P., Steinbach, M., \& Kumar, V., (2006). Introduction to Data Mining, Pearson Education. 
